\title{
Correction to: Carbon pricing and energy efficiency: pathways to deep decarbonization of the US electric sector
}

\author{
Marilyn A. Brown (iD) - Yufei Li
}

Published online: 19 July 2018

(C) Springer Nature B.V. 2018

\section{Correction to: Energy Efficiency https://doi.org/10.1007/s12053-018- 9686-9}

The original publication had two errors. The abstract was not included and figure $3 \mathrm{~b}$ was a repetition of figure 6 . The original publication was updated. 